\title{
Assessment of groundwater ages using radiocarbon and chlorofluorocarbons in West Hawai' $i$ aquifer systems
}

\author{
B.K. OKUHATA ${ }^{1 *}$, A.I. El-KADI ${ }^{1,2}$, H. DUlaI ${ }^{1}$, J.H.

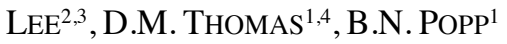 \\ ${ }^{1}$ Department of Earth Sciences, University of Hawai'i at \\ Mānoa, Honolulu, HI 96822, USA (*correspondence: \\ bokuhata@hawaii.edu) \\ ${ }^{2}$ Water Resources Research Center, University of Hawai'i at \\ Mānoa, Honolulu, HI 96822, USA \\ ${ }^{3}$ Department of Civil and Environmental Engineering, \\ University of Hawai'i at Mānoa, Honolulu, HI 96822, \\ USA \\ ${ }^{4}$ Hawai' $i$ Institute of Geophysics and Planetology, University \\ of Hawai'i at Mānoa, Honolulu, HI 96822, USA
}

\begin{abstract}
Residents of Hawai'i rely on groundwater as their primary source of freshwater, yet flow and transport processes in the Hawaiian aquifer systems are still not well understood. The islands are characterized by highly heterogeneous basaltic lava which create a very complex hydrogeologic system. Additionally, the aquifers are often confined by dike systems or intersected with large-scale impermeable layers. All of these subsurface structures affect how groundwater is stored and how quickly it is able to move. The west side of Hawai' $i$ Island (further referred to as West Hawai'i) has an unusual hydraulic head gradient, forming a high-elevation aquifer system that supplies the majority of the area's freshwater demands. To better understand this hydrogeologic system, we employ a multitracer approach to determine apparent groundwater ages. Radiocarbon is utilized to date older water in the aquifer system, while chlorofluorocarbons are utilized to date younger water recharged less than 50 years ago. The compiled information and related analyses will be utilized in understanding the aquifer system's storage and transport characteristics along with existing hydrogeological data sets. The data will be used in model calibration to enhance our predictive capabilities. With this insight, we can better understand the sustainability of West Hawai'i aquifer systems and better manage our groundwater resources.
\end{abstract}

